\title{
Gênero, cor/raça e níveis de letramento em Santa Catarina e Alagoas: um experimento com base em microdados do censo 2000
}

\author{
Alceu Ravanello Ferraro* \\ Jasom de Oliveira**
}

\section{Resumo:}

Valendo-se dos microdados do Censo 2000, o estudo se propôs confrontar as relações de gênero e de cor/raça com níveis de letramento nos estados de Santa Catarina (SC) e Alagoas (AL), estados estes representativos das situações extremas, no país, em termos de educação escolar. O estudo considerou apenas a população jovem de 18 a 24 anos, a qual, pela idade, já poderia/deveria ter concluído a Educação Básica, o que corresponde ao nível 4 de letramento. Esses/as jovens de 18 a 24 anos foram classificados em diferentes níveis de letramento com base na quantidade de anos de estudo cursados com aprovação. Os resultados da análise são basicamente três: primeiro, enquanto que em Santa Catarina predominam os níveis mais elevados de letramento, em Alagoas prevalecem os níveis mais baixos; segundo, em ambos os estados, as mulheres situam-se melhor que os homens do respectivo Estado em termos de níveis de letramento; terceiro, tanto em Santa Catarina como em Alagoas tem-se a seguinte ordem decrescente quanto a níveis de letramento: $1^{\circ}-$ mulheres brancas, $2^{\circ}-$ homens brancos, $3^{\circ}-$ mulheres negras, $4^{\circ}-$ homens negros, ou seja, superioridade ao mesmo tempo da mulher em relação ao homem e da cor/raça branca em relação à negra. Em síntese, ao mesmo tempo em que se mantêm as históricas desigualdades regionais e de cor/raça, as mulheres jovens (de 18 a 24 anos) apresentam melhores níveis de letramento do que os homens da mesma idade. O principal desafio posto por estes resultados está na investigação e no enfrentamento político e pedagógico das causas que, ao mesmo tempo que levam à inversão da relação de desigualdade no que concerne a gênero, mantêm e reproduzem as desigualdades educacionais relacionadas com as variáveis região e cor/raça.

Palavras-chave: Relações homem-mulher. Raças. Alfabetização-Alagoas. Alfabetização-Santa Catarina.

* Doutor em Ciências Sociais pela Pontifícia Universidade Gregoriana, Roma (Itália). Professor titular aposentado da Universidade Federal do Rio Grande do Sul. Pesquisador do CNPq.

** Aluno da Escola Superior de Teologia, São Leopoldo (RS). Bolsista de Apoio Técnico do CNPq. 
Este trabalho é parte do projeto de pesquisa "Escola Brasileira: quem são os excluídos? Alfabetização, escolarização e letramento em relação a classe social, gênero e cor/raça nos censos demográficos", desenvolvido no período de março de 2004 a fevereiro de 2007, com o apoio do CNPq. Ele dá continuidade a experimentos anteriores de construção de níveis de letramento com apoio em dados da Contagem da População 1996 (FERRARO, 1999a, 2002, 2003), aqui retomados com base em microdados do Censo Demográfico 2000.

O objetivo, neste trabalho, é apresentar os resultados de estudo sobre desigualdades regionais quanto a níveis de letramento, em entrecruzamento com as dimensões de gênero e de cor ou raça, com base nos microdados do Censo Demográfico (INSTITUTO BRASILEIRO DE GEOGRAFIA E ESTATÍSTICA, 2000), processados expressamente para tal fim. A novidade, em relação aos estudos anteriores acima citados, manifesta-se sob três ângulos. Primeiro, por se orientar agora o interesse para as relações que as dimensões gênero e cor/raça mantêm com níveis de letramento entre pessoas jovens, de 18 a 24 anos de idade, as quais, teoricamente, pela idade, já poderiam/deveriam ter concluído o Ensino Médio, grau este de ensino que representa o nivel 4 de letramento, como se esclarecerá melhor no decorrer do trabalho. Segundo, pelo fato de, agora, se passar de análises em plano nacional (do Brasil) para o plano regional, comparando duas Unidades da Federação: de um lado, Santa Catarina, um dos estados que mais se destacam em termos de alfabetização e Educação Básica; de outro, Alagoas, que figura entre as Unidades da Federação que apresentam os índices educacionais mais baixos do país (FERRARO; KREIDLOW, 2004, p. 193, gráfico 1). Terceiro, por se recorrer agora aos microdados $^{1}$ do Censo 2000 para a análise desejada.

A relevância da pesquisa está, na visão dos autores, na tentativa de construção de níveis de letramento a partir das estatísticas educacionais oficiais. O propósito, portanto, não é o de discutir o conceito de letramento, mas sim o de, a partir dele, tentar estabelecer niveis de letramento, dando continuidade a experiências desenvolvidas anteriormente pelo primeiro autor deste trabalho e citadas acima. No fundo, estão um fato e uma questão: o fato é que os trabalhos sobre a temática relativamente nova do letramento praticamente não se valem das estatísticas educacionais; a questão concerne 
precisamente à viabilidade de se recorrer às fontes estatísticas no tratamento da temática do letramento.

\section{Sexo ou gênero? Cor ou raça?}

Segundo o Censo 2000 (INSTITUTO BRASILEIRO DE GEOGRAFIA E ESTATÍSTICA, 2000), no Brasil, em todos os grupos desde 5 a 9 até 40 a 44 anos, as mulheres apresentam taxas de alfabetização mais elevadas que os homens, só perdendo para estes nas idades mais avançadas, isto é, a partir de 45 anos. Surpreenderia, hoje, qualquer tentativa de explicar tal fenômeno a partir da variável "sexo", isto é, das características biológicas que distinguem homens e mulheres, e da variável "idade", que opõe, no caso, as pessoas com menos de 45 anos àquelas com 45 anos ou mais anos de idade. O censo coleta informações sobre características mais imediatamente apreensíveis, como ser homem ou mulher e ter determinado número de anos de idade. Seria cômico os recenseadores saírem a perguntar pelo gênero das pessoas entrevistadas ou se estas são (ou se têm como) crianças, adolescentes, adultas ou idosas. Tais categorias prestam-se para a análise e interpretação dos dados coletados, não para a sua coleta. Não deve, portanto, causar admiração que se mantenha nos títulos das tabelas e gráficos o termo sexo, assim como constou nos instrumentos de coleta do censo e figura nas definições das variáveis contempladas nas publicações do Instituto Brasileiro de Geografia e Estatística (IBGE).

Coisa semelhante pode ser dita em relação à variável censitária "cor ou raça". Não faz muito, pôde-se ouvir na televisão: "Preto é cor, negro é raça!" Historicamente, os censos brasileiros, quando o fizeram, levantaram a cor das pessoas. No Censo 2000, que aqui interessa, a variável foi intitulada "cor ou raça", com as seguintes alternativas: branca, preta, parda, amarela, indígena, ignorada. Considerando que os estudos vêm mostrando que é pequena a diferença entre pessoas identificadas como "pretas" e "pardas" no que se relaciona com indicadores educacionais, optou-se por reunir estas categorias censitárias na categoria analítica "negro/a". Da combinação das duas variáveis (sexo e cor/raça) resultaram as quatro categorias analíticas seguintes: mulher branca, homem branco, mulher negra, homem negro, a serem confrontadas em termos de níveis de letramento. Essa seqüência (mulher branca, homem branco, mulher negra, homem negro) expressa 
a hipótese da ordem decrescente que - supunha-se - deveria resultar do cruzamento das variáveis sexo e cor/raça com níveis de letramento.

\section{Gênero e alfabetização}

Há mais de cinqüenta anos estudo da Organização das Nações Unidas para a Educação, a Ciência e a Cultura (UNESCO) fazia duas observações sobre a relação entre sexo e analfabetismo no Brasil. A primeira referia-se à taxa de analfabetismo, notadamente mais elevada entre as mulheres do que entre os homens de 15 anos ou mais, tanto em 1920 como em 1940. Quanto a isto, nada de novo, uma vez que tal constatação acompanhava a tendência mundial de taxas de analfabetismo mais elevadas entre as mulheres do que entre os homens. A segunda observação, apoiada em dados do Censo 1940, desagregados por grupos de idade, identificava uma clara tendência de mudança, porquanto, nesse ano, no agrupamento de 10 a 19 anos, a proporção de analfabetos era praticamente a mesma para ambos os sexos: $57,3 \%$ entre os homens e 57,4\% entre as mulheres. (ORGANIZAÇÃO DAS NAÇÕES UNIDAS PARA A EDUCAÇÃO, A CIÊNCIA E A CULTURA, 1953, p. 41- 42).

$\mathrm{Na}$ realidade, um pequeno detalhe (o agrupamento 10 a 19 anos) levou a UNESCO a uma conclusão equivocada. Com efeito, alguns anos mais tarde, o Conselho Nacional de Estatística (CNE), em sua obra Contribuições para o Estudo da Demografia no Brasil, ao mesmo tempo em que constatava "o gravíssimo atraso da instrução primária no Brasil” e confirmava a histórica "inferioridade feminina" em relação à alfabetização a partir do grupo de 20 a 29 anos, trazia uma novidade importante que pode ser resumida nos três pontos seguintes:

- o aumento da alfabetização fora menor na população masculina de 10 anos e mais (de 48,15\% em 1940 para 52,62\% em 1950) do que na feminina (de $37,99 \%$ para $44,17 \%$ ), o que resultou na atenuação da "inferioridade das mulheres" quanto à alfabetização, a qual, todavia, se mantinha ainda bem marcada;

- tanto em 1940 como em 1950, nos grupos de 5 a 9 anos e de 10 a 14 anos verificava-se, quanto à alfabetização, uma "inferioridade dos meninos em relação às meninas", desvantagem esta que, no censo de 1950, se estendeu também para a faixa de 15 a 19 anos; 
- tal inferioridade dos meninos em relação às meninas quanto à alfabetização se deveria ao fato de os meninos serem aproveitados mais do que as meninas em "trabalhos extradomésticos." (INSTITUTO BRASILEIRO DE GEOGRAFIA E ESTATÍSTICA, 1961, p. 389, 395 e 434).

Está sendo objeto de outros estudos, ainda inéditos, a trajetória da inversão da desigualdade de gênero no que respeita à alfabetização e a outros indicadores educacionais, tais como média de anos de estudo e percentagem de pessoas com pelo menos nível fundamental concluído. Decorrida quase uma década desde a realização do Censo 2000, a superioridade das mulheres em relação aos homens em termos de taxa de alfabetização, que valia para a população até 44 anos, deve ter-se estendido também ao grupo de pessoas de 45 a 49 anos.

Deixa-se de lado, aqui, o exame da hipótese do CNE que atribuía a "inferioridade" dos meninos em termos de alfabetização à maior freqüência dos mesmos em trabalho extradoméstico. Fixa-se a atenção no segundo ponto destacado, isto é, no fato de o CNE ter mantido desagregados os grupos de 5 a 9, 10 a 14 e 15 a 19 anos, o que lhe permitiu detectar um fato absolutamente novo na relação entre gênero e alfabetização no Brasil: a superioridade das meninas em relação aos meninos nos grupos de 5 a 9 e 10 a 14 anos no Censo 1940, fato que o estudo da UNESCO não pudera captar por ter ignorado o grupo de 5 a 9 anos e ter reunido num só os grupos de 10 a 14 e 15 a 19 anos, o que levou aquela entidade a ver igualdade onde começava a manifestar-se desigualdade em sentido contrário - em favor das mulheres a partir de então.

\section{Cor/raça e educação}

O final do século XVIII foi marcado pela emergência do debate sobre a temática da mulher, dos seus direitos, inclusive à educação, e do seu lugar na sociedade (cidadania). Destacaram-se, nesse período, a francesa Gouges (1992, p. 183-202, tradução nossa), com sua La Déclaration des Droits de la Femme e de la Citoyenne (Declaração dos direitos da mulher e da cidadã), de 1791; o francês Marquês de Condorcet (1994, tradução nossa), com suas Cinq mémoires sur l'instruction publique (Cinco memórias sobre a instrução pública), também de 1791; finalmente, a inglesa Wollstonecraft (1983, tradução 
nossa), com sua obra Vindication of the rights of woman (Defesa dos direitos da mulher), de 1792. Esta última obra exerceu forte influência no Brasil, por meio de Nísia Floresta, a primeira feminista brasileira (DUARTE, 2005).

A segunda metade do século XIX, por sua vez, presenciou o surgimento das teorias racistas, com destaque para a obra Essai sur l'inegalité des races humaines (Ensaio sobre a desigualdade das raças humanas), publicada originalmente em quatro volumes, nos anos de 1853 a 1855, de autoria do francês Gobineau (1983, p. 133-1515, tradução nossa), obra de grande influência no Brasil, até pela presença do autor em nosso meio no início dos anos 1870. Segundo Skidmore (1991, p. 7), a entrada no Brasil das doutrinas do racismo científico, especialmente após 1870, colocou em cheque a ideologia assimilacionista, dominante no país. Schwarcz (1993), por sua vez, tem a década de 1870 como um marco na história das idéias no Brasil, destacando o paradoxo representado pelo liberalismo e racismo:

Paradoxo interessante, liberalismo e racismo corporificaram, nesse momento, dois grandes modelos teóricos explicativos de sucesso local equivalentes e no entanto contraditórios: o primeiro fundava-se no indivíduo e em sua responsabilidade pessoal; o segundo retirava a atenção colocada no sujeito para centrá-la na atuação do grupo entendido enquanto resultado de uma estrutura biológica singular. (SCHWARCZ, 1993, p. 14).

Tudo isto é de fundamental importância porque coloca a emergência da questão das relações de gênero e de raça em dois momentos marcados por dois movimentos de reação (reacionários) de tipo ultraliberal: o malthusianismo social, termo cunhado para significar a concepção de pobreza e de política social pública, inclusive educacional, em relação aos pobres, e o darvinismo social, entendido como a lei spenceriana da sobrevivência do mais apto, ambos precursores do movimento neoliberal. Essas questões foram abordadas em textos anteriores (FERRARO, 1997, 1999b) e recentemente retomadas (FERRARO, 2006), especialmente no sentido de rememorar as condições de sua emergência e de avaliar a sua influência nas políticas públicas, particularmente as de educação, no Brasil.

Estudo sobre a constituição do trabalho (trabalhador) livre no Rio Grande do Sul no final do século XIX contém pistas interessantes 
sobre a relação entre raça (escravos e ex-escravos) e educação: “É claro o efeito esperado pelo esforço educacional: moldar o bom cidadão e o bom trabalhador.” (PESAVENTO, 1989, p. 58). Fica a pergunta sobre quanto esse esforço educacional público ultrapassava os rígidos limites recomendados, no início do século XVIII, pelo autor de $A$ fábula das abelhas, a saber, que "os conhecimentos da classe pobre trabalhadora se limitem à esfera de suas ocupações e que nunca se estendam (no que concerne às coisas visíveis) para além do que se relaciona com a sua profissão.” (MANDEVILLE, 2001, p. 190, tradução nossa). Esta questão ganha particular importância quando se lembra que aos escravos era vedado o acesso à escola e que, até a Emenda Constitucional n. 25, de 1985 (BRASIL, 1999, v. VIa), e a Constituição de 1988 (BRASIL, 1997), os analfabetos, sem direito a voto, permaneceram excluídos da cidadania.

No início dos anos 1960 definia-se o termo etnia como grupo biológica e culturalmente homogêneo, dizendo-se que o mesmo não era sinônimo de raça, uma vez que "a palavra raça tem um sentido exclusivamente biológico." (DICIONÁRIO..., 1963, verbete). Retomado nas últimas décadas, o termo "raça" passou a ter uma conotação ao mesmo tempo sócio-cultural e política muito forte. É o que aparecia com clareza, na década de 1980, em texto sobre relações raciais e rendimento escolar:

Resumindo, destaco esses dois fatores que explicariam a diferença de rendimento escolar entre alunos ricos e pobres, brancos e negros: um mecanismo de recrutamento, ou seja, o aluno negro ou o aluno pobre é absorvido pela rede escolar de maneira diferente do aluno de classe média ou não pobre; uma vez constituída essa clientela socialmente homogênea, os professores atuam no sentido de reforçar a crença de que os alunos pobres e negros não são educáveis. (ROSEMBERG, 1987, p. 26).

Jaccoud e Beghin (2002, p. 11 e 65) referem que estudos recentes "evidenciam as desigualdades vivenciadas pelos afro-brasileiros em todas as esferas da vida social" e concluem seu estudo dizendo que o quadro de desigualdade racial por elas apresentado "revela o drama da marginalização econômica e da injustiça social que afeta os afrodescendentes no Brasil". 


\section{Letramento e níveis de letramento}

O termo letramento, criado recentemente no Brasil ${ }^{2}$ (literacia em Portugal), traduz o termo inglês literacy e significa "O estado ou condição que assume aquele que aprende a ler e escrever", como esclarece Soares (1998, p. 17). Segundo a autora, "Letramento é [...] o resultado da ação de ensinar ou de aprender a ler e escrever: o estado ou a condição que adquire um grupo social ou um indivíduo como conseqüência de ter-se apropriado da escrita." (SOARES, 1998, p. 18).

O experimento aqui desenvolvido apóia-se no pressuposto de que a informação sobre o número de anos de estudo cursados com aprovação, levantada pelo IBGE, seja nos censos demográficos, seja em suas Pesquisas Nacionais por Amostra de Domicílios (PNADs), pode ser tomada como base para a definição de diferentes níveis de letramento. Fica, porém, uma questão por resolver: para que se possa construir tais níveis com base nos anos de estudo declarados é necessário definir os pontos onde fazer os cortes, na escala de anos de estudo, que separam os diferentes níveis de letramento. O modelo proposto contempla quatro níveis de letramento, antecedidos pela situação que equivale aproximadamente à condição de analfabetismo absoluto, entendido como tal aquele que corresponde à resposta "não" à pergunta "Sabe ler e escrever...?” dos levantamentos feitos pelo IBGE (censos e PNADs). Têm-se, assim, cinco categorias, construídas com base nos dados censitários sobre anos de estudo da população.

A primeira categoria é constituída pelas pessoas classificadas, nos censos e PNADs, como sem instrução e menos de 1 ano de estudo. Está aí outro indicador de analfabetismo, construído com a informação sobre anos de estudo da população, bastante próximo, em termos de resultado, daquele obtido pela resposta "não" à pergunta "Sabe ler e escrever?". Mas, aqui, impõe-se um esclarecimento importante. Se, de um lado, se pode falar de um analfabetismo absoluto, no sentido de não domínio do alfabeto, o mesmo não se poderia dizer em relação a letramento. Como bem esclarece Tfouni (1988, p. 18), "não existe, nas sociedades modernas, o letramento 'grau zero', que equivaleria ao 'iletramento'." E acrescenta a autora: "Do ponto de vista do processo sócio-histórico, o que existe de fato nas sociedades industriais modernas são 'graus de letramento', sem 
que com isto se pressuponha sua inexistência". Não se poderia, portanto, falar em nível zero de letramento. Ainda assim, parece aos autores deste trabalho que, mesmo admitindo-se que não existe nível zero de letramento nas sociedades modernas como o Brasil, seria impróprio considerar os analfabetos absolutos como tendo nível 1 de letramento. Feito este esclarecimento, passa-se agora a definir os quatro níveis de letramento. Retomam-se aqui definições utilizadas em estudos anteriores para os níveis 1 a 3 de letramento (FERRARO, 2002, 2003).

O nível 1 de letramento compreende todos aqueles que, nos censos e PNADs, informaram ter (ou a respeito dos quais foi informado terem) de 1 a 3 anos de estudo concluídos com aprovação. Esse nível pode ser tido como a realização do mínimo dos mínimos em termos de letramento. Ele sinaliza a ultrapassagem da barreira que se interpõe entre o analfabetismo em sua forma mais cabal (o analfabetismo absoluto no sentido esclarecido) e a realização dos primeiros passos em termos de alfabetização e letramento, o que coincidiria aproximadamente com a conclusão da $1^{\text {a }}$ série do Ensino Fundamental (um ano de estudo), pelo menos, bem como com o conceito censitário de "capacidade de ler e escrever um bilhete simples". É certo que esse nível não assegura ainda a competência necessária para se operar ou praticar no cotidiano, com alguma desenvoltura, a leitura, a escrita e o cálculo, nem é suficiente para tornar improvável a reversão ao analfabetismo no sentido de incapacidade de ler e escrever. No entanto, ele representa, com certeza, duas coisas importantes: de um lado, a libertação dos preconceitos e da estigmatização de que são alvo os analfabetos no Brasil; de outro, a abertura do caminho para os passos seguintes no processo de alfabetização e a ascensão a níveis mais elevados de letramento.

O nível 2 de letramento compreende todas as pessoas com 4 a 7 anos de estudo concluídos, o que corresponde aproximadamente ao antigo primário, mas sem a conclusão do Ensino Fundamental de oito séries, em vigor quando da realização do Censo 2000. A definição desse nível apoia-se na suposição de que a conclusão da $4^{a}$ série do Fundamental representa o alcance de um domínio da leitura, da escrita e do cálculo capaz de permitir à pessoa valer-se no dia-a-dia de tais conhecimentos e técnicas e a partir do qual se tornaria improvável o retorno ao analfabetismo. Enquanto o nível 1 significa libertação do estigma do analfabetismo e abertura do caminho para os níveis seguintes, o nível 2 atesta a aquisição da capacidade mínima 
de operação, por isso também chamado de nível do mínimo operacional em termos de letramento.

O nível 3 representa a realização do mínimo estabelecido pela Constituição de 1988: a conclusão do Ensino Fundamental de oito anos em vigor em 2000. Poderia, por isso, levar também o nome de nível do mínimo constitucional. Toda a população de 15 anos ou mais poderia/ deveria, teoricamente, ter concluído pelo menos essas oito séries.

O nível 4 de letramento é atingido pela conclusão do ensino de nível médio, o que equivalia no ano 2000 a 11 anos de estudo: oito anos de Ensino Fundamental, mais três correspondentes ao Ensino Médio. Este nível de letramento pode ser denominado nível do mínimo constitucional ampliado, nos termos do "dever do Estado" conforme definido pela Constituição Federal, em seu artigo 208, Inciso II - “progressiva universalização do ensino médio gratuito” (BRASIL, 1997), e pelo Estatuto da Criança e do Adolescente, em seu artigo 54, inciso II - "progressiva extensão da obrigatoriedade e gratuidade ao ensino médio” (BRASIL, 2004).

\section{Gênero, cor/raça e educação no Censo 2000}

Tabela 1 - Pessoas de 18 a 24 anos, por níveis de letramento / número de anos de estudo, segundo o sexo e a cor/raça. Santa Catarina e Alagoas, 2000 .

\begin{tabular}{l|c|c|c|c|c|c}
\hline \multirow{2}{*}{$\begin{array}{c}\text { Unidade da } \\
\begin{array}{c}\text { Federação, sexo e } \\
\text { cor/raça }\end{array}\end{array}$} & $\begin{array}{c}\text { Sem } \\
\text { instrução e } \\
\text { menos de } \\
1 \text { ano }\end{array}$ & $\begin{array}{c}1 \text { a 3 } \\
\text { anos } \\
\text { (Nível 1) }\end{array}$ & $\begin{array}{c}4 \text { a } 7 \\
\text { anos } \\
\text { Nível 2) }\end{array}$ & $\begin{array}{c}8 \text { a } 10 \\
\text { anos } \\
\text { Nível 3) }\end{array}$ & $\begin{array}{c}11 \text { anos } \\
\text { ou + } \\
\text { Nível 4) }\end{array}$ & $\begin{array}{c}\text { Não } \\
\text { determinados }\end{array}$ \\
\cline { 2 - 7 } Santa Catarina & 1,7 & 5,3 & 30,1 & 26,3 & 34,7 & 1,8 \\
TOTAL & 1,5 & 4,9 & 28,1 & 25,7 & 38,2 & 1,6 \\
Mulheres & 1,9 & 5,8 & 32,2 & 26,9 & 31,3 & 1,9 \\
Homens & 1,3 & 4,3 & 26,3 & 25,9 & 40,7 & 1,6 \\
Mulheres brancas & 1,6 & 4,9 & 30,2 & 27,6 & 33,8 & 1,8 \\
Homens brancos & 3,2 & 10,6 & 44,5 & 24,1 & 15,7 & 1,9 \\
Mulheres negras & 3,4 & 12,6 & 47,2 & 22,1 & 12,4 & 2,2 \\
Homens negros & 3,4 & & & continua
\end{tabular}


continuação de

\begin{tabular}{|c|c|c|c|c|c|c|}
\hline \multicolumn{7}{|l|}{ Alagoas } \\
\hline TOTAL & 14,2 & 23,2 & 32,1 & 16,6 & 12,5 & 1,2 \\
\hline Mulheres & 11,2 & 20,8 & 33,2 & 18,6 & 15,1 & 1,0 \\
\hline Homens & 17,2 & 25,6 & 31,0 & 14,7 & 9,9 & 1,4 \\
\hline Mulheres brancas & 8,7 & 16,7 & 30,4 & 20,7 & 22,4 & 1,0 \\
\hline Homens brancos & 12,6 & 20,9 & 30,3 & 18,0 & 16,7 & 1,4 \\
\hline Mulheres negras & 12,6 & 23,1 & 34,8 & 17,3 & 11,0 & 1,0 \\
\hline Homens negros & 19,3 & 27,8 & 31,4 & 13,1 & 6,8 & 1,4 \\
\hline
\end{tabular}

Fonte: Instituto Brasileiro de Geografia e Estatística (2000).

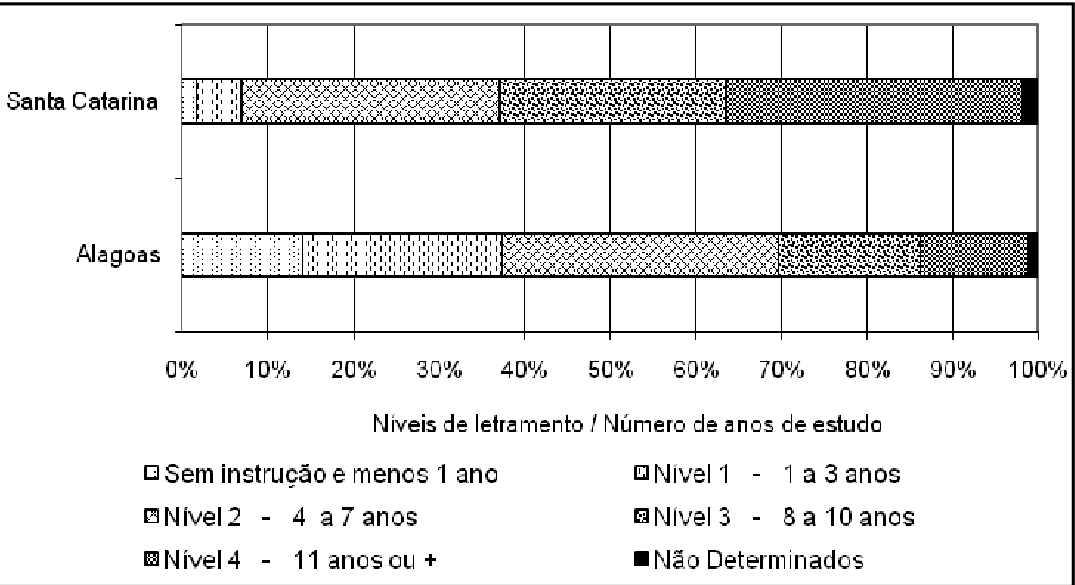

Gráfico 1 - pessoas de 18 a 24 anos, por níveis de letramento/número de anos de estudo. Santa Catarina e Alagoas, 2000.

Fonte: Tabela 1.

Pode-se, agora, aplicar o modelo de níveis de letramento ao estudo de sua relação com gênero e cor/raça. O objetivo não é verificar a trajetória da relação entre gênero e educação, objeto de outros estudos dentro do projeto de pesquisa, mas analisar, numa visão sincrônica, as relações entre gênero, cor/ raça e níveis de letramento entre os/as jovens de 18 a 24 anos no momento do Censo 2000. Os resultados obtidos, para os dois estados selecionados (Santa Catarina e Alagoas), pelo processamento dos microdados do referido censo, constam na Tabela 1 e nos gráficos 1 a 5 .

No primeiro passo confrontam-se os níveis de letramento alcançados pelo referido grupo de jovens de 18 a 24 anos nos dois estados, sem qualquer 
desagregação por gênero e cor/raça, conforme percentuais constantes nas linhas intituladas "TOTAL" na Tabela 1 e respectiva representação no Gráfico 1. Em Santa Catarina, que figura entre os estados com melhores índices educacionais, mais de $1 / 3$ das pessoas de 18 a 24 anos $(37,1 \%)$ sequer haviam concluído o Ensino Fundamental (sem instrução e menos de 1 ano de estudo: 1,7\%; nível 1: 5,3\%; nível 2: 30,1\%). No outro extremo, apenas 34,7\% (pouco mais de 1/3) haviam atingido, nesse estado, o nível 4 de letramento (Ensino Médio concluído), nível esse que teoricamente se podia esperar de todas as pessoas desse grupo de idade.

Incomparavelmente mais grave é a situação no Estado de Alagoas, onde apenas 12,5\% das pessoas de 18 a 24 anos haviam atingido, no ano 2000, o nível 4 de letramento, o equivalente a apenas uma em cada oito pessoas, chegando a quase $70 \%$ o número de jovens de 18 a 24 anos que não haviam atingido o mínimo constitucional de oito anos de estudo, o equivalente ao nível 3 de letramento (sem instrução...: 14,2\%; nível 1: 23,2\%; nível 2: 32,1\%).

Em síntese, num grupo de idade que teoricamente poderia ter atingido o nível 4 (nível médio concluído) e que deveria ter pelo menos alcançado o nível 3 de letramento (Ensino Fundamental completo), observa-se que, respectivamente na melhor situação (Santa Catarina) e na pior (Alagoas), $37,1 \%$ e $69,5 \%$, respectivamente, sequer haviam concluído o Ensino Fundamental ou atingido o nível 3 de letramento.

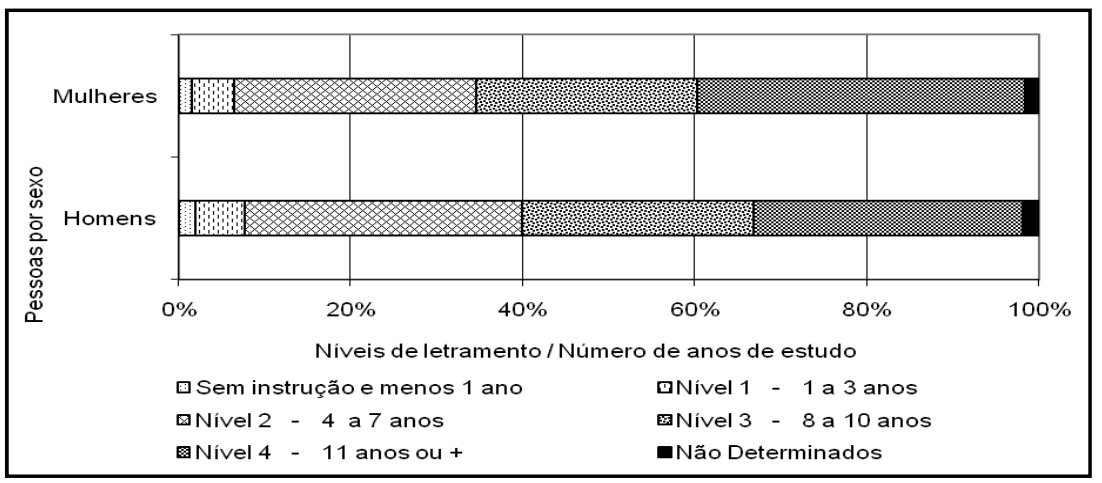

Gráfico 2 - pessoas de 18 a 24 anos, por níveis de letramento/número de anos de estudo segundo o sexo. Santa Catarina, 2000.

Fonte: Tabela 1. 


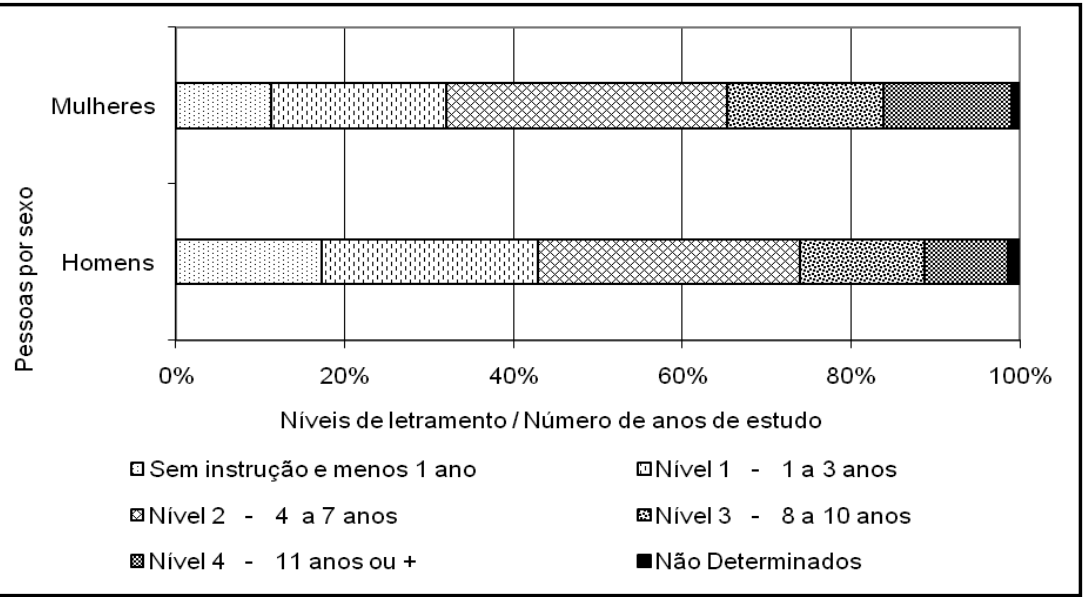

Gráfico 3 - pessoas de 18 a 24 anos, por níveis de letramento/número de anos de estudo segundo o sexo. Alagoas, 2000.

Fonte: Tabela 1.

No segundo passo da análise, introduz-se a variável gênero (Tabela 1 e gráficos 2 e 3). A comparação entre mulheres e homens no grupo de 18 a 24 anos revela duas coisas. A primeira é que as diferenças apuradas entre Santa Catarina e Alagoas em termos de níveis de letramento se mantêm, no referido grupo de idade, tanto para população masculina como para a feminina. A segunda revelação é que, em ambos os estados, as mulheres levam sensível vantagem em relação aos homens em termos de letramento: elas estão menos representadas que os homens na categoria "sem instrução..." e nos níveis mais baixos de letramento, figurando em percentagens mais elevadas nos níveis mais altos de letramento. Em Santa Catarina, a superioridade das mulheres em relação aos homens se manifesta principalmente no nível 4 de letramento, onde figuram 38,2\% das mulheres, contra apenas 31,3\% dos homens, no grupo de pessoas de 18 a 24 anos. Em Alagoas, a vantagem das mulheres, muito mais acentuada do que em Santa Catarina, se estende pelos níveis 2, 3 e 4 de letramento, tocando aos homens percentuais muito mais elevados nas categorias de menor instrução (sem instrução e nível 1 de letramento). Isto confirma tudo que se vem dizendo no país, ultimamente, sobre a crescente vantagem das mulheres em termos dos mais variados indicadores educacionais. 
No terceiro passo da análise introduz-se também a variável cor/ raça, trabalhando-se agora com as quatro categorias analíticas anteriormente definidas (mulher branca, homem branco, mulher negra, homem negro). A tabela 1 e os gráficos 4 (Santa Catarina) e 5 (Alagoas) permitem três observações principais. Primeiramente, em qualquer uma das quatro categorias analíticas consideradas (mulheres brancas, homens brancos, mulheres negras, homens negros) mantém-se acentuada, em termos de níveis de letramento, a desigualdade regional anteriormente apurada entre os dois estados representativos das situações extremas no país - Santa Catarina e Alagoas.

A segunda observação permite identificar com nitidez, em ambos os estados, a seguinte ordem decrescente no que se refere a níveis de letramento atingidos: $1^{\circ}$ lugar - mulheres brancas; $2^{\circ}$ lugar - homens brancos, $3^{\circ}$ lugar - mulheres negras, $4^{\circ}$ lugar - homens negros. Nos níveis mais altos de letramento, as mulheres, tanto brancas como negras, estão sempre melhor representadas do que os homens da mesma cor/raça. Já no outro extremo da escala, ou seja, nos níveis mais baixos de letramento, verifica-se maior presença dos homens em relação às mulheres de mesma cor/raça. Em outras palavras, no grupo de jovens de 18 a 24 anos estudados, em Santa Catarina e em Alagoas as mulheres levam sempre vantagem sobre os homens: as mulheres brancas, vantagem sobre os homens brancos; as mulheres negras, vantagem sobre os homens negros.

A terceira observação que se impõe é que, em qualquer dos dois estados, as desigualdades de cor ou raça são bem mais acentuadas do que as desigualdade de gênero entre pessoas de mesma cor ou raça. Ou seja, as desigualdades educacionais entre mulheres brancas e mulheres negras e entre homens brancos e homens negros são sensivelmente maiores do que as encontradas entre mulheres e homens da mesma cor ou raça. Isto significa que as relações de cor/raça estão determinando desigualdades maiores do que as resultantes das relações de gênero. Com uma ressalva, porém: as desigualdades de gênero, que haviam começado a inverter-se a partir do terceiro quartel do século XX e que foram acentuando-se e continuam a agravar-se a cada novo censo, estão gerando preocupação tanto no campo da pesquisa como nos campos da prática pedagógica e das políticas educacionais, preocupação esta que, há algum tempo, vem centrando a atenção no que costuma ser interpretado como "fracasso dos meninos". 


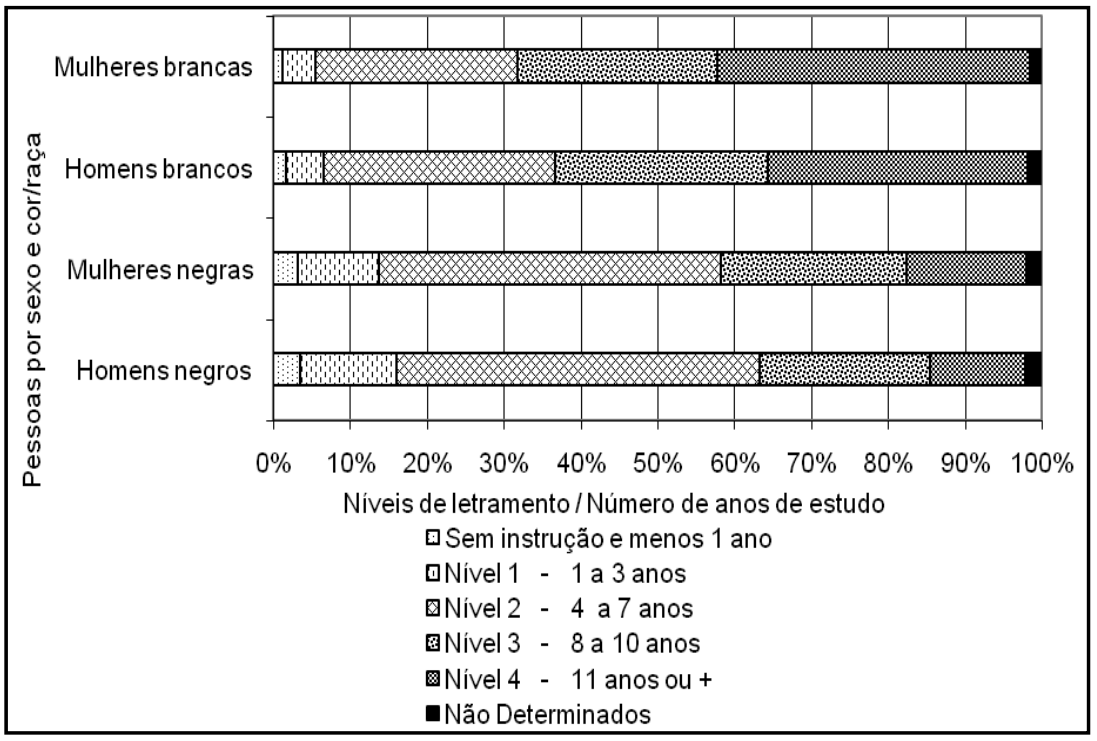

Gráfico 4 - pessoas de 18 a 24 anos, por níveis de letramento/número de anos de estudo segundo o sexo e cor/raça. Santa Catarina, 2000.

Fonte: Tabela 1.

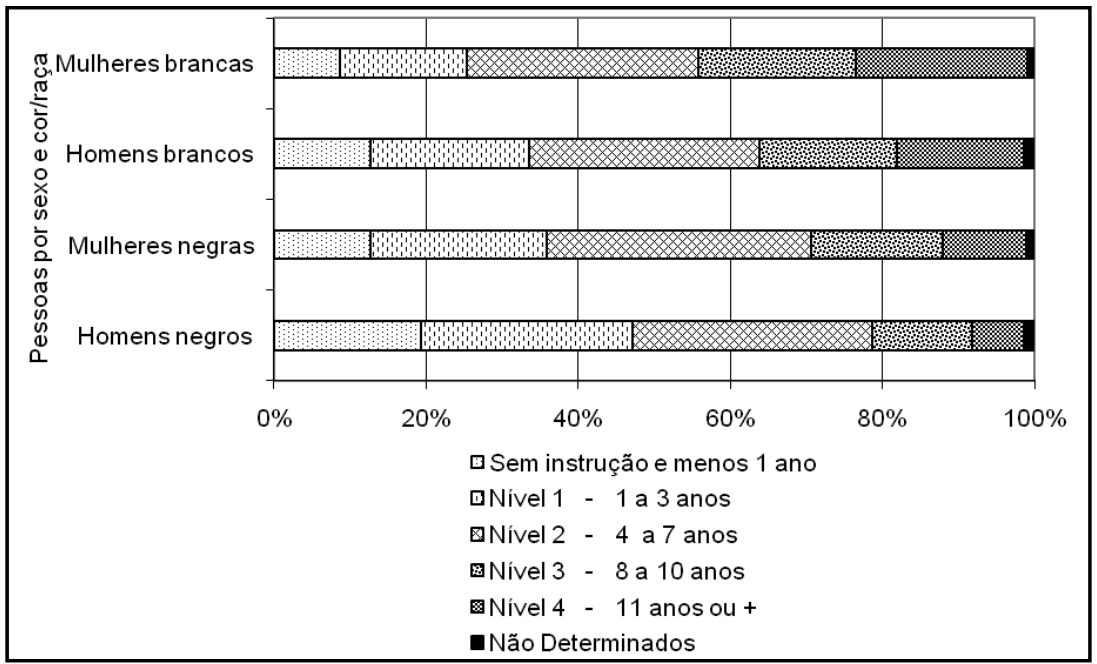

Gráfico 5 - pessoas de 18 a 24 anos, por níveis de letramento/número de anos de estudo segundo o sexo e cor/raça. Alagoas, 2000.

Fonte: Tabela 1. 


\section{Conclusão}

A análise comparativa aqui realizada, envolvendo as relações de gênero e cor/raça com níveis de letramento, no grupo de jovens de 18 a 24 anos, em Santa Catarina e Alagoas, com base no Censo 2000, coloca uma série de desafios tanto à pesquisa quanto à política educacional e à práxis educativa.

O primeiro desafio está na persistência das enormes desigualdades regionais, aqui ilustradas por meio do confronto entre os estados de Santa Catarina e Alagoas, tomados, neste estudo, como representantes das situações extremas no país no que respeita à educação escolar. Santa Catarina, representando o bloco de Unidades da Federação de melhores índices educacionais, constituído por parte do Sudeste (São Paulo e Rio de Janeiro), todo o Sul (Paraná, Santa Catarina e Rio Grande do Sul), mais o Distrito Federal; Alagoas, representando todos os estados do Nordeste brasileiro, mais o estado do Acre, que constituem o bloco de estados com os piores índices educacionais do país. Vale lembrar, ainda, que tais desigualdades foram constituindo-se a partir do final do século XIX, passando a assumir, no decorrer do século XX, a forma de desigualdades tipicamente regionais, como se mostrou em estudo anterior (FERRARO; KREIDLOW, 2004). São, portanto, históricas essas desigualdades e resultantes de processos econômicos, demográficos, políticos e sociais perfeitamente identificáveis na história do país, tais como, entre outros, o deslocamento do centro econômico e político para o Sudeste, a ascensão do ciclo do café, a industrialização e urbanização, os grandes deslocamentos populacionais, seja através de correntes imigratórias vindas do exterior a partir da década de 1820, seja através das migrações internas em direção ao novo centro político-econômico do país. (FERRARO; KREIDLOW, 2004). Como não surgiram do nada, seria no mínimo ingenuidade imaginar que tais desigualdades se possam corrigir por si, com o simples passar dos anos. Somente políticas redistributivas fortes e continuadas poderiam sanálas ou ao menos minorá-las.

O segundo desafio reside nos percentuais alarmantes de pessoas jovens, no grupo de idade de 18 a 24 anos, que não só não atingiram o nível 4 de letramento (conclusão do Ensino Médio ou Educação Básica completa), mas sequer alcançaram o nível 3 (Ensino Fundamental completo 
- o mínimo constitucional). Isto vale para ambos os estados: com maior gravidade para Alagoas, mas com gravidade também para Santa Catarina, como, aliás, para todas as Unidades da Federação, em que pese o trombeteio que, desde meados da década de 1980, insiste em anunciar a boa nova da universalização do acesso à escola no Brasil (FERRARO, 1999c). É preciso esclarecer que por acesso à escola deve-se entender, não apenas o ingresso de todos na escola alguma vez na vida, mas a realização universal pelo menos do Ensino Fundamental completo que a Constituição de 1988 reconhece e consagra como direito público subjetivo.

O terceiro desafio refere-se à reconstituição da trajetória e à compreensão do significado e do alcance social e político do fato de as mulheres estarem progressivamente superando os homens em termos dos mais variados indicadores educacionais. De um lado, parece que isto não autoriza a que se dê sumariamente por superada a desigualdade social da mulher que historicamente tem marcado as relações de gênero. Até porque essa corrida da mulher, especialmente da mulher negra, em busca de escolarização pode dever-se também a exigências maiores postas pelo mercado para o mesmo emprego e mesmo salário. De outro lado, fica a questão das consequências para os meninos/homens dados por fracassados no processo de escolarização. Mesmo que não se concorde com o termo e o enfoque do "fracasso escolar" (FERRARO, 2004), há ali um problema grave, que desafia ao mesmo tempo a compreensão, a prática pedagógica e as políticas públicas de educação.

O quarto desafio é posto pelo fato mesmo da permanência e reprodução persistente da histórica desigualdade educacional que atinge a população afro-descendente em confronto com a população que o censo classifica como branca no Brasil. Está posto ali um elemento importante a ser levado em conta na discussão a respeito das políticas afirmativas relacionadas com a questão étnico-racial.

Por último, o quinto desafio orienta a atenção para o estudo das lógicas particulares, diferenciadas, que podem estar regendo a ação dos diferentes fatores - como região, gênero e cor/raça - sobre a escolarização e letramento da população. Em outras palavras, os efeitos produzidos pelas dimensões regional, racial e de gênero não são algo que se possa simplesmente adicionar. Cada dimensão tem sua lógica particular. Com efeito, mulheres e homens distribuem-se aproximadamente na mesma proporção nas diferentes regiões, nos diferentes grupos étnico-raciais e nas diferentes classes sociais. Mulheres 
negras e homens negros se distribuem de maneira fortemente desigual entre as diferentes regiões e estados brasileiros: Bahia, por exemplo, tem proporcionalmente mais pessoas negras do que os estados da Região Sul. Embora a dimensão classes sociais não tenha sido considerada neste estudo, inúmeras pesquisas sobre o assunto autorizam a supor que a população negra concentra-se fortemente na classe trabalhadora e, dentro desta, nas camadas mais fragilizadas, como as de empregados domésticos e trabalhadores sem carteira assinada. Obviamente, com salários mais baixos.

Como se disse, o estudo aqui desenvolvido constitui um experimento, uma tentativa de se construir uma escala de níveis de letramento com base nos dados censitários sobre anos de estudos da população. Na seqüência, o debate poderia voltar-se para as seguintes direções: primeiro, para a pertinência de se falar em níveis de letramento; segundo, para a propriedade de se recorrer a estatísticas educacionais para a construção de tais níveis; terceiro, para a adequação da escala em si de níveis de letramento aqui utilizada.

\section{Notas}

1 Os microdados, acessíveis em CDs ou DVDs que podem ser adquiridos junto ao IBGE, permitem ao pesquisador processar as informações censitárias individuais (de cada pessoa ou domicílio), de maneira a construir os cruzamentos e tabulações que mais interessem à sua pesquisa.

2 Em texto de Magda Soares (1998, p. 15) tem-se um breve resgate da chegada, na segunda metade da década de 1980, do novo termo "letramento” ao vocabulário da Educação e das Ciências Linguísticas.

\section{Referências}

BRASIL. Constituição da República Federativa do Brasil: promulgada em 5 de outubro de 1988. 17. ed. atual. e ampl. São Paulo: Saraiva, 1997. (Coleção Saraiva de Legislação).

BRASIL. Lei 8.069, de 13.07.1990: estatuto da criança e do adolescente e legislação correlata. São Paulo: Revista dos Tribunais, 2004.

BRASIL. Senado Federal. Constituições Brasileiras: 1969. Brasília, 1999. v. VIa. 
CONDORCET, Marie Jean Antoine Nicolas de Caritat, Marquis de. Cinq mémoires sur l'instruction publique: 1791. Présentation, notes, bibliographie et chronologie par Charles Coutel et Catherine Kintzler. Paris: GarnierFlammarion, 1994, 380 p. Disponível em: <http://classiques.uqac.ca/ classiques/condorcet/cinq_memoires_instruction/Cinq_memoires_ instr_pub.pdf >. Acesso em: 8 maio 2008.

DICIONÁRIO de sociologia. Porto Alegre: Globo, 1963.

DUARTE, Constância Lima. Nísia Floresta: a primeira feminista do Brasil. Florianópolis: Ed. Mulheres, 2005.

FERRARO, Alceu Ravanello. Alfabetizar é escolarizar. Sociedade e Estado, Brasília, v. 24, n. 2, p. 323-348, jul./dez. 1999a.

- Analfabetismo e níveis de letramento no Brasil: o que dizem os censos. Educação \& Sociedade, Campinas, SP, v. 23, n. 81, p. 21-47, dez. 2002.

. Diagnóstico da escolarização no Brasil. Revista Brasileira de Educação, Campinas, SP, n. 12, p. 22-47, set./dez. 1999c.

. Escola Brasileira: quem são os excluídos? Alfabetização, escolarização e letramento em relação a classe social, gênero e cor/raça nos censos demográficos. Canoas, RS, 2004-2007. Projeto de pesquisa apoiado pelo CNPq e desenvolvido no Centro Universitário La Salle.

Escolarização no Brasil na ótica da exclusão. In: MARCHESI, Álvaro; HERNÁNDEZ GIL, Carlos (Org.). Fracasso escolar. Tradução Ernani Rosa. Porto Alegre: ARTMED, 2004. p. 48-65.

. História quantitativa da alfabetização no Brasil. In: RIBEIRO, Vera Masagão (Org.). Letramento no Brasil: reflexões a partir do INAF 2001. São Paulo: Global, 2003. p. 195-207.

O movimento neoliberal: gênese, natureza e trajetória. Sociedade em Debate, Pelotas, RS, v. 3, n. 9, p. 33-58, dez. 1997.

. Neoliberalismo e políticas sociais: a naturalização da exclusão.

Estudos Teológicos, São Leopoldo, RS , v. 45, n. 1, p. 99-117, 2005.

Neoliberalismo e políticas sociais: um pé em Malthus outro em Spencer. Universidade e Sociedade, Brasília, n. 20, p. 21-33, set./dez. 1999b. 
FERRARO, Alceu Ravanello; KREIDLOW, Daniel. Analfabetismo no Brasil: configuração e gênese das desigualdades regionais. Educação \& Realidade, Porto Alegre, v. 29, n. 2, p. 179-200, jul./dez. 2004.

GOBINEAU, Arthur. Oevres: I. Paris : Gallimard, 1983. Essai sur l'inegalité des races humaines.p. 133-1515.

GOUGES, Olympe de. La déclaration des droits de la femme et de la citoyenne d'Olympe de Gouges: 1791. In: NOACK, Paul. Olympe de Gouges: coutisane et militante dês droits de la femme. Traduit de L 'allemand par Isablle Duclos. Paris : Fallois, 1992. p. 185-196.

INSTITUTO BRASILEIRO DE GEOGRAFIA E ESTATÍSTICA. Censo Demográfico 2000. [Brasília], 2000. DVDs de Microdados.

. Conselho Nacional de Estatística. Laboratório de Estatística. Contribuição para o estudo da demografia no Brasil. Rio de Janeiro: IBGE, 1961. Parte C: Alfabetização. p. 387-448.

JACCOUD, Luciana; BEGHIN, Nathalie. Desigualdades raciais no Brasil: um balanço da intervenção governamental. Brasília: IPEA, 2002.

MANDEVILLE, Bernard. La fabula de las abejas o los vicios privados hacen la prosperidad publica. Comentario crítico, histórico y explicativo de F. B. Kaye. México: Fondo de Cultura Económica, 2001.

NOACK, Paul. Olympe de Gouges: Coutisane et militante des droits de la femme. Traduit de L 'allemand par Isabelle Duclos. Paris: Fallois, 1992.

ORGANIZAÇÃO DAS NAÇÕES UNIDAS PARA A EDUCAÇÃO, A CIÊNCIA E A CULTURA (UNESCO). L'analphabétisme dans divers pays: étude statistique préliminaire sur la base des recensements effectués depuis 1900. Paris, 1953.

PESAVENTO. Sandra. A emergência dos subalternos: trabalho livre e ordem burguesa. Porto Alegre: Ed. UFRGS/ FAPERGS, 1989.

ROSEMBERG, Fúlvia. Relações raciais e rendimento escolar. Cadernos de Pesquisa, São Paulo, n. 63, p. 19-23, nov. 1987.

SCHWARCZ, Lilia Morits. O espetáculo das raças: cientistas, instituições e questão racial no Brasil: 1870-1930. 5. reimpr. São Paulo: Companhia das Letras, 1993. 
SKIDMORE, Thomas E. Fato e mito: descobrindo um problema racial no Brasil. Cadernos de Pesquisa, São Paulo, n. 79, p. 5-16, 1991.

SOARES, Magda. Letramento: um tema em três gêneros. Belo Horizonte: Autêntica, 1998.

TFOUNI, Leda Verdiani. Adultos não alfabetizados: o avesso do avesso.

Campinas, SP: Pontes, 1988.

WOLLSTONECRAFT, Mary. Vindication of the rights of woman.

Harmondsworth, Middlesex: Penguin English Library, 1983. 
Gender, color/race and literacy rates in Santa Catarina and Alagoas: an experiment based on micro data from the 2000 census

\section{Abstract:}

Using micro-data from the 2000 Census, the study proposes to confront the relations of gender and color and race with literacy levels in Santa Catarina (SC) and Alagoas (AL) states, which are representative of extreme situations in the country in terms of school education. The study only considered young people from $18-24$, who, because of their age, could or should have finished elementary school, which corresponds to level 4 literacy. These young people from 18-24 were classified in different literacy levels based on the number of years of study they had passed. The study had three main findings: first, while higher levels of literacy predominate in Santa Catarina, in Alagoas the lowest levels predominate; second, in both states, women have better literacy levels than men; third Santa Catarina as well as Alagoas has the following decreasing order in the literacy levels: 1 st - white women, 2nd - white men, 3rd - black women, 4 th - black men, that is, superiority of both women in relation to men and of whites in relation to blacks. In summary, while historic regional inequalities are maintained and those of color and race, young women from $18-24$ have better literacy levels than men of the same age. The
Género, color/raza y niveles de letramento en Santa Catarina y Alagoas (Brasil): un experimento con base en micro-datos del censo del año 2000

\section{Resumen:}

A partir de los datos del Censo de 2000, el presente estudio se propone confrontar las relaciones de género, color y raza con los niveles de letramento en las provincias de Santa Catarina (SC) y Alagoas (AL) Brasil, siendo estas provincias representativas de situaciones extremas del país en términos de educación escolar. El estudio consideró apenas los jóvenes entre 18 y 24 años, que por su edad ya deberian/podrían haber finalizado la educación básica, que corresponde al nivel 4 de letramento. Estos jóvenes fueron clasificados en diferentes niveles de letramento teniendo como base la cantidad de años cursados y aprobados. Los resultados del análisis de la investigación son básicamente tres: primeramente, en cuanto en Santa Catarina predominan los niveles más elevados de letramento, en Alagoas prevalecen los niveles más bajos, segundo, en ambas provincias, la situación de las mujeres está mejor que las de los hombres de cada provincia en términos de letramento, tercero, tanto en santa Catarina como en Alagoas se verificó la siguiente orden decreciente en relación al letramento: 1 - mujeres blancas, 2 - hombres blancos, 3 - mujeres negras, 4 - hombres negros, es decir, tenemos al mismo tiempo una superioridad 
main challenge presented by these results is in the investigation and political and pedagogical confrontation of the causes, which, while they lead to an inversion in the relationship of inequality concerning gender, maintain and reproduce the educational inequalities related with the variables of region, color and race.

Key words: Relations men-women. Races. Literacy - Alagoas. Literacy Santa Catarina. de la mujer en relación al hombre y del color/raza blanca en relación a la negra. En síntesis al mismo tiempo en que se mantienen las históricas desigualdades regionales y de color/raza, las mujeres jóvenes (de 18 a 24 años) representan mejores niveles de letramento que los hombres de la misma edad. El principal desafío colocado por estos resultados está en la investigación y en el enfrentamiento político y pedagógico de las causas que, al mismo tiempo que llevan a la inversión de la relación de desigualdad en lo concerniente al género, mantiene y reproducen las desigualdades educacionales relacionadas con las variables región y color/raza.

Palabras-clave: Relaciones hombre mujer. Raza. Alfabetización. - Alagoas. Alfabetización - Santa Catarina.

\section{Alceu Ravanello Ferraro}

Centro Universitário La Salle, Canoas/RS

Endereço: Rua Dona Laura, 924 - apto. 201

Bairro Rio Branco

CEP: 90430-090

Porto Alegre-RS

Telefone: 0xx51- 30129014

Fax: 0xx51- 33884890

E-mail:aferraro@adufrgs.ufrgs.br

\section{Jasom de Oliveira}

Escola Superior de Teologia, São Leopoldo/RS

Endereço: Rua Amadeo Rossi, 467

Morro do Espelho

CEP: 93030-220

São Leopoldo-RS

Telefone: 0xx51-8134 8565

E-mail:jasom@est.com.br 